\title{
Safety and Efficacy of Aspirin Desensitization Combined With Long-Term Aspirin Therapy in Aspirin-Exacerbated Respiratory Disease
}

Li R', Luo F²

'Department of General Medicine, West China Hospital of Sichuan University, Chengdu, China

${ }^{2}$ Department of Respiratory Medicine, West China Hospital of Sichuan University, Chengdu, China

J Investig Allergol Clin Immunol 2020; Vol. 30(5): 327-333

doi: 10.18176/jiaci.0433

\begin{abstract}
Objectives: To assess the safety and efficacy of Aspirin desensitization combined with long-term Aspirin therapy in patients with Aspirinexacerbated respiratory disease (AERD).

Methods: We searched the PubMed, Ovid, Cochrane Library, and Google Scholar databases from inception to October 2018 for articles in English. We only included randomized controlled trials and parallel or cross-over studies in which adults with AERD were randomly assigned to undergo Aspirin desensitization and receive long-term Aspirin therapy or placebo.

Results: A total of 869 citations were retrieved, and 6 studies met the criteria for analysis. All studies indicated that nasal symptoms, asthma symptoms, or both improved significantly after Aspirin desensitization. In addition, most studies reported a decline in corticosteroid dosage (oral and inhaled). The 4 studies that reported nasal polyps did not demonstrate a change in nasal polyps with Aspirin therapy compared with placebo. The dropout rates in all studies reviewed ranged from $5.8 \%$ to $55.7 \%$, and the most common adverse events were gastrointestinal symptoms.

Conclusions: Clearly, Aspirin desensitization and treatment are beneficial for AERD patients, with relief of nasal symptoms, improvement in asthma control, decrease in daily corticosteroid use, and no fatal adverse events. However, the long-term adverse effects of Aspirin desensitization and optimal dosage of Aspirin merit further investigation.
\end{abstract}

Key words: AERD. Aspirin desensitization. Efficacy. Adverse events.

\section{Resumen}

Objetivos: Evaluar la seguridad y la eficacia de la desensibilización a la Aspirina junto con la terapia a largo plazo con Aspirina en sujetos con enfermedad respiratoria exacerbada por Aspirina (AERD).

Métodos: Se realizaron búsquedas en PUBMED, Ovid, Cochrane Library y Google Scholar desde el inicio hasta octubre de 2018, e impusimos una restricción del inglés en el idioma de publicación. Solo se incluyeron ensayos controlados aleatorios, paralelos o cruzados, en los cuales los sujetos adultos con AERD se asignaron al azar para recibir desensibilización a la Aspirina y terapia con Aspirina a largo plazo o placebo. Resultados: Se recuperaron un total de 869 citas y 6 estudios cumplieron con los criterios de análisis. Todos los estudios indicaron que los síntomas nasales, los síntomas del asma o ambos mejoraron significativamente después del tratamiento de desensibilización con Aspirina. La mayoría de los estudios mostraron una disminución de la dosis de corticosteroides, orales o inhalados que necesitaron los pacientes. Los cuatro estudios que documentaron pólipos nasales no demostraron un cambio en los pólipos nasales con la terapia con Aspirina en comparación con el placebo. Las tasas de deserción en todos los estudios revisados varían entre el 5,8\% y el 55,7\% y los efectos adversos más comunes fueron los síntomas gastrointestinales.

Conclusiones: Claramente, la desensibilización y el tratamiento con Aspirina son beneficiosos para los pacientes con AERD, con una reducción de los síntomas nasales, mejoras en el control del asma y una disminución del uso diario de corticosteroides, sin eventos adversos fatales. Sin embargo, los efectos secundarios a largo plazo de la desensibilización a la Aspirina y la dosis óptima de la Aspirina merecen más investigación.

Palabras clave: Enfermedad respiratoria exacerbada por Aspirina. Desensiblización a la Aspirina. Eficacia. Aspirina. 


\section{Introduction}

Aspirin-exacerbated respiratory disease (AERD) is an inflammatory disorder. It is also referred to as "Samter's Triad", that is, nasal polyps, asthma, and sensitivity to Aspirin [1]. AERD is now the preferred term in the USA, whereas in other areas, such as some European countries and the Middle East, the term NSAID-exacerbated respiratory disease (NERD) is preferred. The cyclooxygenase (COX) inhibitor plays a critical role in the pathogenesis of AERD.

The 2 mainstream opinions on the pathogenesis of AERD to date recognize the critical role of leukotrienes. One opinion is based on arachidonic acid metabolism disorder. Aspirin is a potent COX-1 inhibitor. Like other nonselective nonsteroidal anti-inflammatory drugs (NSAIDs), it blocks a route for the metabolism of arachidonic acid, thus reducing the synthesis of prostaglandins, including prostaglandin $\mathrm{E}_{2}\left(\mathrm{PGE}_{2}\right)$. However, an alternative pathway, 5-lipoxygenase (5-LO), is still viable and leukotriene levels are increased; leukotriene $\mathrm{E}_{4}\left(\mathrm{LTE}_{4}\right)$ is elevated to the same extent as other leukotrienes and is the most widely measured because of its stability. The other opinion is based on type 2 inflammatory response. Allergens, viral infections, and various environmental factors are all capable of initiating epithelial injury. Injured epithelia release thymic stromal lymphopoietin, IL-25, and IL-33. These cytokines have multiple effects on the early stages of type 2 inflammatory responses [2], type 2 innate lymphoid cells (ILC2), mast cells, and eosinophils involved in the production of leukotrienes, which enhance the type 2 response. $\mathrm{LTE}_{4}$ seems to play a dominant role [3]. One study reported that patients with AERD had higher baseline $\mathrm{LTE}_{4}$ levels than patients with Aspirintolerant asthma [4]. Platelets are also involved in the production of leukotrienes in patients with AERD [5,6].

AERD is acquired and can appear at any time, with the most common age of onset being around 30 years. The incidence of AERD is higher in females [7,8]. In addition, the literature to date provides no accurate data about the prevalence of this disease in the general population. Nevertheless, AERD is prevalent in some countries, whereas in others, such as China, it is rare [9].

The clinical presentations of AERD vary markedly, from absence of symptoms or minimal wheezing to severe respiratory compromise. Some patients report no respiratory symptoms for years (eg, nasal congestion, postnasal drip, coughing, and wheezing), and the only remarkable detail in the history might be previous intolerance to Aspirin or other NSAIDs. Other patients experience rhinitis, asthma, or both, and their conditions are chronic and difficult-to-control with routine treatments, whose effect is not lasting, thus seriously impairing quality of life.

Routine treatment options in AERD include corticosteroids, desensitization, and surgery. Compared with corticosteroids and surgery, desensitization provides long-lasting efficacy. Although numerous studies have highlighted the long-term clinical benefits of desensitization in patients with AERD, most have been criticized for being nonexperimental or lacking a control group not receiving Aspirin therapy. We therefore conducted a systematic review of randomized controlled trials (RCTs) focusing on the long-term efficacy and related adverse effects of Aspirin desensitization in AERD.

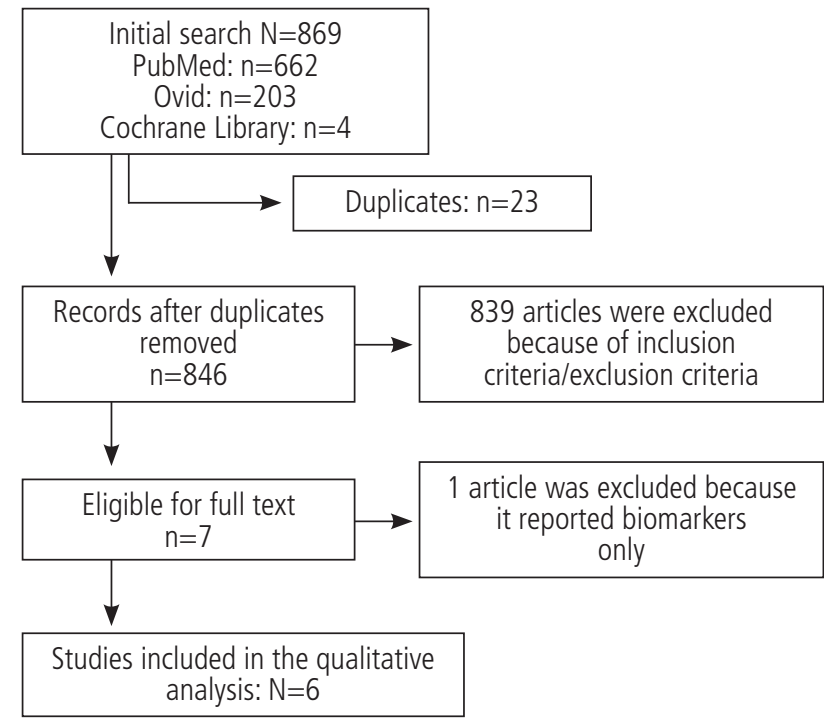

Figure. Search flow diagram.

\section{Methods}

\section{Literature Search}

We conducted a computerized literature search of the PubMed, Ovid, Cochrane Library, and Google Scholar databases. The search included articles published from inception to October 2018. The search criteria were MeSH terms, key words, and a combination of the two. The MeSH terms applied were "Asthma, Aspirin-Induced", and the key words were "Aspirin-exacerbated respiratory disease", "Aspirin desensitization". Two authors performed the literature search independently and compared their results. Our inclusion criteria were as follows: (1) study population comprising only AERD patients or a substantial percentage of AERD patients; (2) Aspirin desensitization as the primary intervention; (3) RCTs; (4) human study population; and (5) only articles in English. The exclusion criteria were as follows: (1) studies reporting only biochemical markers; (2) unpublished studies. The reference lists were screened to identify additional eligible studies. The flow diagram for the search is shown in the Figure.

Table 1. Quality Assessment

\begin{tabular}{cccccccc}
\hline Study & A & B & C & D & E & F & Total \\
\hline 1984 & 1 & 1 & 1 & 1 & 1 & 0 & 5 \\
2007 & 1 & 0 & 1 & 1 & 1 & 0 & 4 \\
2013 & 1 & 1 & 1 & 1 & 1 & 0 & 5 \\
2014 & 1 & 1 & 1 & 1 & 1 & 0 & 5 \\
2015 & 1 & 1 & 1 & 1 & 1 & 1 & 6 \\
2017 & 1 & 1 & 1 & 1 & 1 & 1 & 6 \\
\hline
\end{tabular}

Abbreviations: $A$, random sequence generation; $B$, allocation concealment; $C$, blinding of participants and personnel; $D$, incomplete outcome data; $E$, selective reporting; $F$, other sources of bias. 


\section{Quality Assessment and Data Extraction}

One author assessed the quality of the study and the other retrieved data. The Cochrane collaboration's tool for assessing risk of bias was used for its ability to reliably evaluate RCTs. The risk of bias was assessed based on 6 items with 1 point for a low risk of bias and zero points for a high risk or unclear risk, with a maximum of 6 points indicating the lowest risk of bias and the highest quality. The quality of the studies is shown in Table 1. The data retrieved were the name of the first author and the year of publication, the number of participants in each group, participants' sex and age, interventions, length of follow-up, and outcomes. The general characteristics of the 6 studies included in this review are shown in Table 2. Disagreements were resolved by discussion to reach a consensus.

\section{Results}

Our initial search yielded 306 articles (PubMed, 149; Ovid, 153; Cochrane Library, 4; Google Scholar, 0). After removing 14 duplicates, 292 articles were left, and 285 were excluded after a review of the titles and abstracts. The full text of the 7 remaining articles was reviewed. We excluded 1 study because it was a part of another trial and reported biomarkers only. The final 6 articles on which the qualitative assessment was based [10-15] comprised 5 randomized placebo-controlled trials $[10-13,15]$ and 1 randomized double-blind crossover study [14]. The year of publication of these studies ranged from 1984 to 2017 . Two studies were conducted in the Scripps Clinic and The Scripps Research Institute [12,14], 2 studies were conducted in Iran [10,13], 1 in Poland [15], and 1 in

Table 2. Summary of Studies Included and Clinical Outcomes Between Intervention Group and Placebo Group ${ }^{a}$

\begin{tabular}{|c|c|c|c|c|c|c|c|c|}
\hline \multirow{2}{*}{$\begin{array}{l}\text { Author } \\
\text { Year }\end{array}$} & \multicolumn{3}{|c|}{ Intervention Group } & \multicolumn{3}{|c|}{ Placebo Group } & \multirow[t]{2}{*}{ Follow-up } & \multirow[t]{2}{*}{ Outcomes } \\
\hline & No. & $\mathrm{M} / \mathrm{F}$ & $\begin{array}{c}\text { Mean (SD) } \\
\text { Age, y }\end{array}$ & No. & $\mathrm{M} / \mathrm{F}$ & $\begin{array}{c}\text { Mean (SD) } \\
\text { Age, y }\end{array}$ & & \\
\hline 2017 & 22 & NA & $33(2)$ & 19 & $10 / 9$ & $29(1)$ & $6 \mathrm{mo}$ & $\begin{array}{l}\text { - SNOT-22: } P=.001 \\
\text { - Lund-Mackay score: } P=.229 \\
\text { - Symptom score: } P=.005 \\
\text { - Medication score: } P=.017 \\
\text { - FEV }: P=.032\end{array}$ \\
\hline 2015 & 18 & $5 / 13$ & $\begin{array}{c}31 \\
(4.3)\end{array}$ & 16 & $6 / 10$ & $\begin{array}{c}27 \\
(5.5)\end{array}$ & $6 \mathrm{mo}$ & $\begin{array}{l}\text { - FEV }: P=.015 \\
\text { - SNOT-22: } P=.015 \\
\text { - Symptom score: } P=.014 \\
\text { - Medication score: } P=.138 \\
\text { - Lund-Mackay score: } P=.102\end{array}$ \\
\hline 2014 & 12 & $3 / 9$ & $\begin{array}{l}48.5 \\
(18)\end{array}$ & 8 & $2 / 6$ & $\begin{array}{l}39.5 \\
(27)\end{array}$ & $6 \mathrm{mo}$ & $\begin{array}{l}\text { - SNOT-20: } P=.04 \\
\text { - ACQ score: } P=.037 \\
\text { - ICS dosage: } P=.03 \\
\text { - PNIF: } P=.001\end{array}$ \\
\hline 2013 & 36 & $19 / 17$ & $\begin{array}{c}44.9 \\
(11.3)\end{array}$ & 34 & $20 / 14$ & $\begin{array}{c}45.9 \\
(10.4)\end{array}$ & $36 \mathrm{mo}$ & $\begin{array}{l}\text { - Overall nasal and paranasal complaints: } P=.0019 \\
\text { - Quality of life impairment by nasal and } \\
\text { paranasal complaints: } P=.0083 \\
\text { - General health condition: } P=.029 \\
\text { - Symptom score: } P<.0001\end{array}$ \\
\hline $2007(1)$ & 50 & NA & NA & & Baseline & & $12 \mathrm{mo}$ & $\begin{array}{l}\text { - No. of hospitalizations for asthma/y: } P<.0001 \\
\text { - Nasal sinus score: } P<.0001 \\
\text { - Smell score: } P<.0001 \\
\text { - Asthma score: } P<.03 \\
\text { - Systemic corticosteroid: } P<.0001\end{array}$ \\
\hline $2007(2)$ & 55 & NA & NA & & Baseline & & & $\begin{array}{l}\text { - No. of hospitalization for asthma/y: } P<.0001 \\
\text { Nasal sinus score: } P<.0001 \\
\text { - Smell score: } P<.0001 \\
\text { - Asthma score: } P<.001 \\
\text { - Systemic corticosteroid: } P<.0001\end{array}$ \\
\hline 1984 & 19 & NA & $\begin{array}{c}\text { Median } \\
\text { (IQR), } \\
45(18-71)\end{array}$ & 19 & NA & $45(18-71)$ & $7 \mathrm{mo}$ & $\begin{array}{l}\text { - Nasal congestion symptom scores: } P=.05 \\
\text { - Nasal symptom scores for sinus pain: } P=.05 \\
\text { - Nasal symptom scores for sense of smell: } P=.057 \\
\text { - Combined nasal symptom scores: } P=.05 \\
\text { - Combined chest symptom scores: } P=\text { N.S }\end{array}$ \\
\hline
\end{tabular}

Abbreviations: ACQ, Asthma Control Questionnaire; FEV 1, forced expiratory volume in 1 second; ICS, inhaled corticosteroids; NA, not applicable; NS, nonsignificant; PNIF, peak nasal inspiratory flow; SNOT, Sino-Nasal Outcome Test questionnaire.

aalues for age are shown as mean (SD) unless otherwise indicated. 
Germany [11]. The length of follow-up ranged from 6 months to 36 months.

AERD was diagnosed based on Aspirin challenge: 4 studies $[11,12,14,15]$ used an oral challenge test and 2 studies $[10,13]$ used an intranasal ketorolac and oral Aspirin challenge test. Desensitization was carried out with maintenance Aspirin dosages spanning from $100 \mathrm{mg}$ daily to $625 \mathrm{mg} 4$ times daily.

\section{Asthma Control and Rhinitis/Nasal Symptoms}

When compared with the placebo group, all 6 RCTs reported significant clinical improvements in asthma control and rhinitis/nasal symptoms after at least 6 months of followup. These improvements were expressed as a decreased score in questionnaires or self-reported symptoms, improvements in objective measurements, and reductions in the dosage of corticosteroids for nasal insufflations and bronchial inhalation and systemic corticosteroids. All 6 studies reported relief of symptoms in the upper airway, lower airway, or both. The first randomized double-blind cross-over trial of 25 patients conducted by Stevenson et al [14] revealed a significant improvement in upper airway symptoms (eg, runny nose, nasal congestion, postnasal discharge, sinus pain, and altered sense of smell) compared with lower airway symptoms (eg, chest tightness, wheezing, coughing, and shortness of breath). The authors found that 16 patients had experienced fewer symptoms of severe asthma or rhinitis. Of these, 10 patients experienced fewer asthma symptoms during Aspirin desensitization. In addition, significant differences were recorded between the Aspirin group and placebo group for the mean daily nasal symptom score $(P<.05)$.

The large study of 137 patients by Lee et al [12] found that the group of patients who received $325 \mathrm{mg}$ bid experienced a significant decrease in nasal/sinus symptoms $(P<.0001)$ and asthma symptoms $(P<.001)$, as well as an improvement in their sense of smell $(P<.0001)$. Another group of patients receiving

Table 3. Dropout Rate and Adverse Effects

\begin{tabular}{|c|c|c|c|c|}
\hline Author/Year & $\begin{array}{c}\text { Adverse } \\
\text { Effects, No }\end{array}$ & $\begin{array}{l}\text { Dropout } \\
\text { Rate }\end{array}$ & $\begin{array}{l}\text { Aspirin-Related } \\
\text { Adverse Effects }\end{array}$ & Other \\
\hline 1984 & 13 & $34.2 \%$ & $\begin{array}{l}\text { Aspirin group: } \\
\text { Gastrointestinal pain } 3 \\
\text { Worsening of asthma symptoms } 3 \\
\text { Placebo group: } \\
\text { Worsening of nasal congestion } 1 \\
\text { Uterine bleeding } 1\end{array}$ & Uncooperative 5 \\
\hline 2007 & 32 & $16 \%$ & $\begin{array}{l}325 \text { mg bid group: } \\
\text { Dyspepsia } 9 \\
\text { Asthma } 1 \\
\text { Ecchymosis } 1 \\
\text { Urticaria } 3 \\
\text { Tinnitus } 1 \\
650 \text { mg bid group: } \\
\text { Dyspepsia } 3 \\
\text { Asthma } 3 \\
\text { Ecchymosis } 1 \\
\text { Bleeding } 2 \\
\text { Angioedema } 1\end{array}$ & $\begin{array}{l}\text { Patient jailed } 1 \\
\text { Myalgia } 1 \\
\text { Pregnancy } 1 \\
\text { Unknown } 4\end{array}$ \\
\hline 2013 & 39 & $55.7 \%$ & None & $\begin{array}{l}\text { No motivation } 9 \\
\text { Moved away } 8 \\
\text { Other disease } 8 \\
\text { No adherence } 4 \\
\text { Pregnancy } 3 \\
\text { No subjective benefit } 2 \\
\text { Revision surgery advised } 2 \\
\text { Unknown } 3\end{array}$ \\
\hline 2014 & 5 & $25 \%$ & $\begin{array}{l}\text { Aspirin group: } \\
\text { Dyspepsia } 4 \\
\text { Placebo group: } \\
\text { None }\end{array}$ & Lack of improvement 1 \\
\hline 2015 & 2 & $5.8 \%$ & $\begin{array}{l}\text { Aspirin group: } \\
\text { Gastrointestinal pain } 1 \\
\text { Skin rash } 1 \\
\text { Placebo group: } \\
\text { None }\end{array}$ & None \\
\hline 2017 & 3 & $13.6 \%$ & $\begin{array}{l}\text { Aspirin group: } \\
\text { Gastrointestinal bleeding } 1 \\
\text { Placebo group: } \\
\text { None }\end{array}$ & $\begin{array}{l}\text { Lost } 1 \\
\text { Pregnancy } 1\end{array}$ \\
\hline
\end{tabular}


$650 \mathrm{mg}$ bid experienced similar improvements in nasal and asthma symptoms and sense of smell.

The study with the longest follow-up period (36 months) focused mainly on upper airway symptoms and reported a clear reduction in nasal airway obstruction, postnasal drip, coughing, and sneezing in the Aspirin group compared with the placebo group after low-dose desensitization with $100 \mathrm{mg}$ daily $(P<.0001)[11]$.

A further 3 studies found that compared with the placebo group, patients in the Aspirin group had better sinonasal quality of life, as assessed by the Sino-Nasal Outcome Test questionnaire (SNOT-20 or SNOT-22) and symptom score for nasal symptoms, ocular symptoms, and bronchial symptoms such as cough, difficulty breathing, and wheezing $[10,13,15]$.

Three studies reported forced expiratory volume in 1 second $\left(\mathrm{FEV}_{1}\right)$ as an outcome for assessing asthma control $[10,13,15] ; 1$ of the studies reported peak expiratory flow (PEF) and peak nasal inspiratory flow (PNIF) [15]. SwierczynskaKrepa et al [15] found no statistically significant differences in $\mathrm{FEV}_{1}$ and $\mathrm{PEF}$ values throughout the 6-month Aspirin desensitization, whereas PNIF values increased significantly in patients with Aspirin-induced asthma compared with baseline $(P=.001)$. Esmaeilzadeh et al [10] found that after 6 months of follow-up, participants in the Aspirin group had significantly higher $\mathrm{FEV}_{1}$ than at baseline (87.1 [1.7] vs 79.1 [1.9], $\left.P=.001\right)$ and than the placebo group (87.1 [1.7] vs 80.1 [1.8], $P=.015)$. In addition, a recent study from Iran reported a similar result $(P=.032)$ [13].

Only 1 of the 6 studies [11] reported the inhaled corticosteroid (ICS) dosage or systemic corticosteroid dosage. Stevenson et al [14] reported that 20 of 25 patients received prednisone therapy and that 14 of these received the same or a lower dosage of prednisone after Aspirin desensitization, thus suggesting decreased disease severity. Lee et al [12] showed that the daily systemic corticosteroid dosage decreased by 3 -fold from $3.9 \mathrm{mg} / \mathrm{d}$ to $1.3 \mathrm{mg} / \mathrm{d}(P<.0001)$ and that the intranasal corticosteroid dosage also decreased significantly $(P<.0005)$, while the ICS dosage did not change significantly $(P<.37)$ in patients taking Aspirin $325 \mathrm{mg}$ bid after 1 year of follow-up. The group of patients taking $650 \mathrm{mg}$ bid experienced a similar decrease in the systemic corticosteroid dosage, from $4.0 \mathrm{mg} / \mathrm{d}$ to $1.1 \mathrm{mg} / \mathrm{d}(P<.0001)$. SwierczynskaKrepa et al [15] showed a reduction in the use of ICS combined with Aspirin compared with placebo $(P=.03)$ [15]. In contrast, Esmaeilzadeh et al [10] showed no difference in treatment with Aspirin. In addition, Mortazavi et al [13], who followed the approach of Esmaeilzadeh et al, demonstrated a statistically significant difference $(P=.017)$ in the medication score between the 2 groups.

\section{Polyp Recurrence and the Lund-Mackay Score}

Nasal endoscopy was performed in 4 studies $[10,11,13,15]$. Fruth et al [11] classified the endoscopic outcomes of polyposis using a 0-3 polyp score; recurrence of polyps was regarded as a score of 1 or more. After a 36-month follow-up, the results demonstrated no statistically significant differences between the 2 groups: recurrence of polyps was observed in 8 of 13 patients $(62 \%)$ in the placebo group and in 5 of 18 patients (28\%) in the Aspirin group. However, these data indicate that Aspirin desensitization might help to reduce recurrence of nasal polyps, because the nasal polyposis score of the Aspirin group was lower $(P=.0702)$. The other 3 studies used the Lund-Mackay score based on the sinus CT scan to assess nasal polyps more objectively but found no significant changes between the Aspirin group and the placebo group.

\section{Asthma Attacks, Adverse Events, and Dropouts}

Clinical efficacy is a critical component that should be taken into account when determining the optimal dosage of Aspirin for desensitization therapy. However, Aspirinrelated adverse effects are nonnegligible. All but 1 study [11] included in our review reported Aspirin-related adverse effects (Table 3). Stevenson et al [14] were the first to conduct an RCT on 38 patients with AERD; only 25 competed the trial, and 13 dropped out because of adverse effects ( 8 in the Aspirin group, 5 in the placebo group). Asthma symptoms worsened in 3 patients, and a further 3 experienced gastrointestinal pain and stopped therapy [14].

Lee et al [12] investigated the effect of Aspirin desensitization with different maintenance dosages in 137 patients, of whom 70 were randomized to take $325 \mathrm{mg}$ bid and 67 to take $650 \mathrm{mg}$ bid. Dyspepsia was recorded in 9 patients in the $325 \mathrm{mg}$ bid group and in 3 in the other group (9/70 vs 3/67, respectively). One and 3 patients, respectively, discontinued therapy because of asthma attacks [12]. Another RCT enrolled 70 patients who received low-dose Aspirin (100 mg daily). Only 31 patients completed the study, and 39 discontinued Aspirin over the 3-year follow-up. The dropout rate reached $55.7 \%$, although no-one dropped out because of Aspirin-related adverse effects. Three RCTs reported that 4 of 20 (20\%) [15], 1 of 34 (3\%) [10], and 1 of $22(5 \%)$ [13] patients dropped out because of adverse gastrointestinal effects such as gastrointestinal bleeding and dyspepsia. Mortazavi et al [13] reported that 14 out of 38 patients experienced at least 1 asthma attack. Of the 14 patients, 9 were in the placebo group and 5 in the Aspirin group. No statistically significant differences were observed in rates of asthma attack between the 2 groups. Esmaeilzadeh et al [10] reported similar results throughout the study (RR, 2; 95\%CI, 0.79-5.06; $P=.137$ ).

\section{Discussion}

This review identified 6 RCTs [10-15] assessing the effects of Aspirin desensitization in patients with AERD. The studies reported changes in upper and lower respiratory tract symptoms, daily ICS dosage, lung function, nasal polyp relapse, and adverse effects after placebo and Aspirin therapy. All 6 studies indicated that nasal symptoms, or asthma symptoms, or both improved significantly after Aspirin desensitization. One study indicated that PNIF values increased from baseline, and another 2 studies reported an improvement in $\mathrm{FEV}_{1}$ compared with patients who did not undergo the intervention. Of the 5 studies reporting the corticosteroid dose, 4 found a decrease. Of the 4 studies assessing nasal polyps, no significant changes were noted between the placebo and the Aspirin groups. Of all the studies, dropout rates ranged from $5.8 \%$ to $55.7 \%$; the most common adverse events were gastrointestinal symptoms, such as abdominal pain, gastrointestinal bleeding, and dyspepsia. 
Rare complications included Aspirin-related bleeding, skin rash, ecchymosis, tinnitus, and myalgia. In addition, only patients in the Aspirin group experienced adverse gastrointestinal effects, whereas those in the placebo group did not.

After careful assessment of the medical databases we searched, we were able to identify only 6 RCTs [10-15]. However, we found several open-label studies that provided more information on this topic. In 1990, an observational cohort study enrolled 66 participants taking Aspirin and 40 who were not. During the mean follow-up of 3.8 years, the sense of smell and asthma control had improved and corticosteroid use decreased in participants who had been desensitized to Aspirin. In the Aspirin group, 30 participants dropped out because of gastrointestinal intolerance [16]. In 2003, the same group surveyed 173 participants by telephone and compared outcomes between the first year of Aspirin desensitization and the previous year of Aspirin treatment. Adverse effects, mainly gastrointestinal tract symptoms, led to discontinuation of therapy in $14 \%$ of participants [17].

In 2013, Comert et al [18] conducted a trial to investigate the efficacy of $300 \mathrm{mg}$ daily of Aspirin in the treatment of persons with AERD. A total of 40 patients were enrolled and treated with Aspirin $300 \mathrm{mg} / \mathrm{d}$ for a median (IQR) of 31.5 (10.5-48.5) months. The authors reported that the annual rates of use of systemic corticosteroids and episodes of sinusitis were significantly lower at 1 year and 3 years of follow-up. Furthermore, symptoms of nasal congestion, postnasal drainage, and sense of smell improved significantly.

In 2016, another study in Poland enrolled 14 AERD patients who were followed up for 3 months with Aspirin $650 \mathrm{mg} / \mathrm{d}$ and analyzed the changes in clinical symptoms and blood and urine values. Eight patients completed the treatment. Nasal symptoms decreased by $50 \%-60 \%$, and the mean increase in PNIF values (48\%) was significant, although asthma control improved only slightly, with unchanged $\mathrm{FEV}_{1}$. Urine levels of cysteinyl leukotrienes and $\mathrm{LTE}_{4}$ and prostaglandin $\mathrm{D}_{2}$ metabolite did not change after Aspirin desensitization [19].

In addition to the studies mentioned above, several other trials indicated that Aspirin desensitization could significantly improve the prognosis of AERD in terms of sinus and bronchial symptoms, recurrence of nasal polyps, lung function, and daily corticosteroid use $[20,22-24]$. It seems that these nonrandomized trials yielded better results, possibly because of the difficulty in performing RCTs in AERD. Clearly, Aspirin desensitization and treatment have benefited many AERD patients worldwide. Patients read about and their referring physicians know the benefits of this treatment. Furthermore, patients experience immediate relief following desensitization. Consequently, there would be no "blinding", since, if patients received placebo and this did not relieve symptoms, then Aspirin would be easily obtained. This hypothesis indirectly supports the effectiveness of the drug.

Desensitization, which starts at a low dosage of Aspirin and gradually increases over time, often 3 days, is an alternative approach for AERD. A 1-day desensitization procedure, which is common in the USA, is also justified, because it is safe and effective $[25,26]$. During desensitization, the drug-induced symptoms gradually become milder, last for less time, and finally disappear. The final dose is usually recommended as a maintenance Aspirin dose to be taken at home. However, the actual maintenance dose of Aspirin varies depending on the individual physician. As mentioned above, the maintenance dose ranges from $100 \mathrm{mg}$ daily to $650 \mathrm{mg}$ twice daily. It is not clear whether there is a dose-response relationship in Aspirin desensitization. Some evidence suggests that the daily Aspirin dose correlated with clinical improvement, although we did not confirm this in our analysis [14]. In 2007, Lee et al [12] found that, in terms of clinical improvement, a fairly equivalent effect was found with $325 \mathrm{mg}$ bid of Aspirin and $650 \mathrm{mg}$ bid. However, the populations of both these studies were small, and the dropout rates were high, thus making it difficult to generalize and ensure the robustness of the results. Therefore, clinical trials with a larger sample size are needed to determine whether there is a dose-response relationship in persons with AERD undergoing Aspirin desensitization. Individualized desensitization treatment strategies will be needed in the future.

In 2013, Fruth et al [11] conducted a study with a maintenance dose of $<300 \mathrm{mg}$ daily; this is the only study in our review that reported no Aspirin-related adverse effects. It is logical to speculate that $100 \mathrm{mg}$ of Aspirin daily may be an optimal dosage for desensitization, with fewer adverse effects and benefits that are equivalent to those of a higher dose. However, the high dropout rate might be an obstacle to the achievement of a lower dose through desensitization. Actually, a retrospective analysis of adverse effects such as increased asthma symptoms and nasal congestion showed that we cannot rule out the possibility that patients had a simultaneous viral infection of the upper respiratory tract at the beginning of the trial and dropped out because of socalled adverse effects. Furthermore, Aspirin desensitization is a long-term therapy that can last years, and patients with AERD require relatively higher doses of Aspirin than patients who require Aspirin for other conditions, such as primary prevention of cardiovascular events [27]. We must determine the long-term safety of Aspirin ( 5 years, 10 years, $>10$ years) and identify indicators that enable us to discontinue treatment in the case of adverse events.

Clearly, Aspirin desensitization and treatment are beneficial for AERD patients, with a reduction in nasal symptoms and daily corticosteroid use and improvements in asthma control. However, in clinical practice, safety is more important than efficacy. Hence, it is necessary to investigate the long-term adverse effects of Aspirin desensitization and to identify indicators for discontinuation of therapy. We should make every attempt to determine the optimal dosage of Aspirin tailored to the individual patient with minimal adverse effects and maximal benefits.

\section{Funding}

The authors declare that no funding was received for the present study.

\section{Conflicts of Interest}

The authors declare that they have no conflicts of interest.

\section{References}

1. Samter M, Beers RF, Jr. Concerning the nature of intolerance to aspirin. J Allergy. 1967;40(5):281-93. 
2. von Moltke J, Ji M, Liang HE, Locksley RM. Tuft-cell-derived IL-25 regulates an intestinal ILC2-epithelial response circuit. Nature. 2016;529(7585):221-5.

3. Christie PE, Tagari P, Ford-Hutchinson AW, Charlesson S, Chee $P, A r m$ JP, et al. Urinary leukotriene E4 concentrations increase after aspirin challenge in aspirin-sensitive asthmatic subjects. Am Rev Respir Dis. 1991;143(5 Pt 1):1025-9.

4. Micheletto C, Visconti M, Tognella S, Facchini FM, Dal Negro RW. Aspirin induced asthma (AIA) with nasal polyps has the highest basal LTE4 excretion: a study vs AIA without polyps, mild topic asthma, and normal controls. Eur Ann Allergy Clin Immunol. 2006;38(1):20-3.

5. Mitsui C, Kajiwara K, Hayashi H, Ito J, Mita H, Ono E, et al. Platelet activation markers overexpressed specifically in patients with aspirin-exacerbated respiratory disease. J Allergy Clin Immunol. 2016;137(2):400-11.

6. Laidlaw TM, Boyce JA. Platelets in patients with aspirinexacerbated respiratory disease. J Allergy Clin Immunol. 2015;135(6):1407-14; quiz 15.

7. Berges-Gimeno MP, Simon RA, Stevenson DD. The natural history and clinical characteristics of aspirin-exacerbated respiratory disease. Ann Allergy Asthma Immunol. 2002;89(5):474-8.

8. Szczeklik A, Nizankowska E, Duplaga M. Natural history of aspirin-induced asthma. AIANE Investigators. European Network on Aspirin-Induced Asthma. Eur Respir J. 2000;16(3):432-6.

9. Fan Y, Feng S, XiaW, Qu L, Li X, Chen S, et al.Aspirin-exacerbated respiratory disease in China: a cohort investigation and literature review. Am J Rhinol Allergy. 2012;26(1):e20-2.

10. Esmaeilzadeh H, Nabavi M, Aryan Z, Arshi S, Bemanian $\mathrm{MH}$, Fallahpour $\mathrm{M}$, et al. Aspirin desensitization for patients with aspirin-exacerbated respiratory disease: A randomized double-blind placebo-controlled trial. Clin Immunol. 2015; 160(2):349-57.

11. Fruth K, Pogorzelski B, Schmidtmann I, Springer J, Fennan $\mathrm{N}$, Fraessdorf $\mathrm{N}$, et al. Low-dose aspirin desensitization in individuals with aspirin-exacerbated respiratory disease. Allergy. 2013;68(5):659-65.

12. Lee JY, Simon RA, Stevenson DD. Selection of aspirin dosages for aspirin desensitization treatment in patients with aspirinexacerbated respiratory disease. J Allergy Clin Immunol. 2007;119(1):157-64.

13. Mortazavi N, Esmaeilzadeh $H$, Abbasinazari M, Babaie $D_{\text {, }}$ Alyasin S, Nabavizadeh $\mathrm{H}$, et al. Clinical and Immunological Efficacy of Aspirin Desensitization in Nasal Polyp Patients with Aspirin-Exacerbated Respiratory Disease. Iran J Pharm Res. 2017;16(4):1639-47.

14. Stevenson DD, Pleskow WW, Simon RA, Mathison DA, Lumry WR, Schatz $M$, et al. Aspirin-sensitive rhinosinusitis asthma: a double-blind crossover study of treatment with aspirin. J Allergy Clin Immunol. 1984;73(4):500-7.

15. Swierczynska-Krepa M, Sanak M, Bochenek G, Strek P, Cmiel A, Gielicz A, et al. Aspirin desensitization in patients with aspirin-induced and aspirin-tolerant asthma: a double-blind study. J Allergy Clin Immunol. 2014;134(4):883-90.

16. Sweet JM, Stevenson DD, Simon RA, Mathison DA. Longterm effects of aspirin desensitization--treatment for aspirinsensitive rhinosinusitis-asthma. J Allergy Clin Immunol. 1990;85(1 Pt 1):59-65.

17. Berges-Gimeno MP, Simon RA, Stevenson DD. Long-term treatment with aspirin desensitization in asthmatic patients with aspirin-exacerbated respiratory disease. J Allergy Clin Immunol. 2003;111(1):180-6.

18. Comert S, Celebioglu E, Yucel T, Erdogan T, Karakaya G, Onerci $\mathrm{M}$, et al. Aspirin $300 \mathrm{mg} /$ day is effective for treating aspirinexacerbated respiratory disease. Allergy. 2013;68(11):1443-51.

19. Makowska JS, Olszewska-Ziaber A, Bienkiewicz $B$, Lewandowska-Polak A, Kurowski M, Wozniakowski B, et al. Clinical benefits of aspirin desensitization in patients with nonsteroidal anti-inflammatory drug exacerbated respiratory disease are not related to urinary eicosanoid release and are accompanied with decreased urine creatinine. Allergy Asthma Proc. 2016;37(3):216-24.

20. Rozsasi A, Polzehl D, Deutschle T, Smith E, Wiesmiller K, Riechelmann $H$, et al. Long-term treatment with aspirin desensitization: a prospective clinical trial comparing 100 and $300 \mathrm{mg}$ aspirin daily. Allergy. 2008;63(9):1228-34.

21. Waldram J, Walters K, Simon R, Woessner K, Waalen J, White A. Safety and outcomes of aspirin desensitization for aspirinexacerbated respiratory disease: A single-center study. J Allergy Clin Immunol. 2018;141(1):250-6.

22. Spies JW, Valera FC, Cordeiro DL, de Mendonca TN, Leite MG, Tamashiro E, et al. The role of aspirin desensitization in patients with aspirin-exacerbated respiratory disease (AERD). Braz J Otorhinolaryngol. 2016;82(3):263-8.

23. Celikel S, Stevenson D, Erkorkmaz U, White AA. Use of nasal inspiratory flow rates in the measurement of aspirininduced respiratory reactions. Ann Allergy Asthma Immunol. 2013;111(4):252-5.

24. Berges-Gimeno MP, Simon RA, Stevenson DD. Early effects of aspirin desensitization treatment in asthmatic patients with aspirin-exacerbated respiratory disease. Ann Allergy Asthma Immunol. 2003;90(3):338-41.

25. Pelletier T, Roizen G, Ren Z, Hudes G, Rosenstreich D, Jerschow E. Comparable safety of 2 aspirin desensitization protocols for aspirin exacerbated respiratory disease. J Allergy Clin Immunol Pract. 2019;7(4):1319-21.

26. DeGregorio GA, Singer J, Cahill KN, Laidlaw T. A 1-Day, 90-Minute Aspirin Challenge and Desensitization Protocol in Aspirin-Exacerbated Respiratory Disease. J Allergy Clin Immunol Pract. 2019;7(4):1174-80.

27. McNeil JJ, Wolfe R, Woods RL, Tonkin AM, Donnan GA, Nelson MR, et al. Effect of Aspirin on Cardiovascular Events and Bleeding in the Healthy Elderly. $\mathrm{N}$ Engl J Med. 2018;379(16):1509-18.

\section{- Manuscript received May 10, 2019; accepted for publication July 3, 2019.}

\section{- Fengming Luo}

Department of Respiratory Medicine
West China Hospital
Sichuan University
37 Guoxue Street
610041 Chengdu
China
E-mail: fengmingluo@outlook.com

J Investig Allergol Clin Immunol 2020; Vol. 30(5): 327-333 